\title{
Characterizing marshland compressibility by an in-situ loading test: design and set-up of an experiment in the Venice Lagoon
}

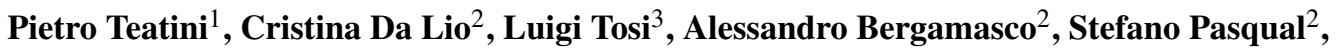 \\ Paolo Simonini ${ }^{1}$, Veronica Girardi ${ }^{1}$, Paolo Zorzan ${ }^{1}$, Claudia Zoccarato ${ }^{1}$, Massimiliano Ferronato ${ }^{1}$, \\ Marcella Roner $^{4}$, Marco Marani ${ }^{1}$, Andrea D’Alpaos ${ }^{4}$, Simonetta Cola ${ }^{1}$, and Giuseppe Zambon ${ }^{1, *}$ \\ ${ }^{1}$ Department of Civil, Environmental and Architectural Engineering, University of Padova, Padova, 35131, Italy \\ ${ }^{2}$ Institute of Marine Sciences, CNR, Venice, 30122, Italy \\ ${ }^{3}$ Institute of Geosciences and Earth Resources, CNR, Padova, 30131, Italy \\ ${ }^{4}$ Department of Geosciences, University of Padova, Padova, 30131, Italy \\ *retired \\ Correspondence: Pietro Teatini (pietro.teatini@unipd.it)
}

Published: 22 April 2020

\begin{abstract}
The fate of coastal marshlands in the near future will strongly depend on their capability to maintain their elevation above a rising mean sea level. Together with the deposition of inorganic sediments during high tides, organic soil production by halophytic vegetation, and organic matter decomposition, land subsidence due to natural soil compression is a major factor controlling the actual elevation of salt-marsh platforms. Due to their high porosity and compressibility, the marsh sedimentary body undergoes large compression because of the load of overlying more recent deposits. The characterization of the geotechnical properties of these deposits is therefore of paramount importance to quantify consolidation versus accretion and relative sea level rise. However, undisturbed sampling of this loose material is extremely challenging and lab tests on in-situ collected samples are not properly representative of in-situ conditions due to the scale effects in highly heterogeneous silty soils such as those of the Venice lagoon. To overcome this limitation, an in-situ loading test was carried out in the Lazzaretto Nuovo salt-marsh in the Venice Lagoon, Italy. The load is obtained by a number of plastic tanks that are filled with seawater, reaching a cumulative load of $40 \mathrm{kN}$ applied on a $2.5 \times 1.8 \mathrm{~m}^{2}$ surface. Specific instrumentations were deployed before positioning the tanks to measure soil vertical displacement at various depths below the load $(0,10$, and $50 \mathrm{~cm})$ and distances $(0,40$, and $80 \mathrm{~cm})$ from the load centre. Moreover, six pressure transducers were used to record overpressure dissipation over time. The collected datasets will be interpreted through a 3-D flow-deformation model that, once calibrated, provides reliable estimates of the compressibility values for each monitored depth interval.
\end{abstract}

\section{Introduction}

Characterizing the hydrogeological and geomechanical properties of recent deposits, i.e. the top soils of prograding Holocene deltas, estuaries, and lagoon landforms, is very challenging and, simultaneously, of paramount importance. The difficulties mainly arise from the high porosity and compressibility of these loose sediments (e.g., Brain et al., 2015) together with heterogeneous nature of many sedimentary de- posits such as those investigated in this study (Cola and Simonini, 2002), that hamper the possibility of collecting undisturbed samples for laboratory testing. The significance of the physical characterization of these shallow soils is at least twofold. From a geological perspective, sediments in coastal transitional environments are considered (paleo-)sea level proxies and provide precise and near-continuous reconstructions of relative sea level over the last millennia (Brain et al., 2017). However, deriving the past sea level evolution 
from a marsh stratigraphy is challenging. Because of the large porosity typical of newly formed landforms, shallow deposits experience a significant compaction (Allen, 1999; Cahoon et al., 2002; Jankowski et al., 2017; Zoccarato et al., 2018), with the ongoing consolidation over a certain depth range depending on the load of the overlying more recent deposits (Brain et al., 2015). If auto-compaction is improperly accounted for or neglected, inaccurate reconstructions of sea level rise, land subsidence, and sedimentation rates are obtained (Morton et al., 2000; Serandrei-Barbero et al., 2006).

A second key aspect is related to the resilience of transitional coastal ecosystems. In fact, the fate of these landforms in the next decades will be strictly connected to their capability to keep their height with respect to a rising mean sea level. The loss of relative elevation because of land subsidence, erosion, decrease of sedimentation, and/or sea level rise can cause the loss of large portions of these environments or the shift of lagoon tidal marshes to a less environmentally valuable state, e.g. tidal flats. This is ongoing, for example, in the Mississippi delta, Louisiana (Törnqvist et al., 2008), and in the Venice Lagoon, Italy (Marani et al., 2010), respectively. Auto-compaction of Holocene deposits occurs on the top of regional land subsidence due to tectonics, consolidation of deep formations, glacial and sediment isostatic adjustment, and fluid withdrawal from the subsurface (Da Lio et al., 2018). Depending on the hydro-geomechanical properties of the recent deposits, auto-compaction can significantly enhance the regional land subsidence (Zoccarato and Teatini, 2017), with a nonlinear feedback between sedimentation, compaction, and accretion. This is generally neglected in morphological models developed to investigate the possible evolution of transitional environments in relation to the expected climate change or sedimentation scenarios (Lesser et al., 2004; D'Alpaos and Marani, 2016).

Until now, the properties of these soils have been estimated through empirical relationships and lab tests. Brain et al. (2015) and van Asselen et al. (2011) linked void ratio at $1 \mathrm{kPa}\left(e_{0}\right)$, the compression $\left(C_{\mathrm{c}}\right)$, and re-compression $\left(C_{\mathrm{r}}\right)$ indices to the percentage of organic matter quantified through the loss on ignition (LOI). Cola et al. (2008) and Brain et al. (2017) collected samples at various depths in the upper 1 to $2 \mathrm{~m}$ soil range from the San Felice marsh, Venice Lagoon, and the East River Marsh in Connecticut, respectively, and estimated the main geomechanical parameters $\left(C_{\mathrm{c}}, C_{\mathrm{r}}\right.$, the yield stress $\sigma_{v}^{\prime}$ and the Young modulus $E$ ) from onedimensional compression tests at a stress level corresponding to the site overburden stress.

However, the representativeness of these data is questionable because sampling these loose soils in undisturbed conditions in highly challenging. To avoid problematic generalizations or challenges related to soil sampling and lab testing at very small stresses, an original in-situ loading test has been planned and carried out in July 2019 on a tidal marsh of the Venice Lagoon, Italy.

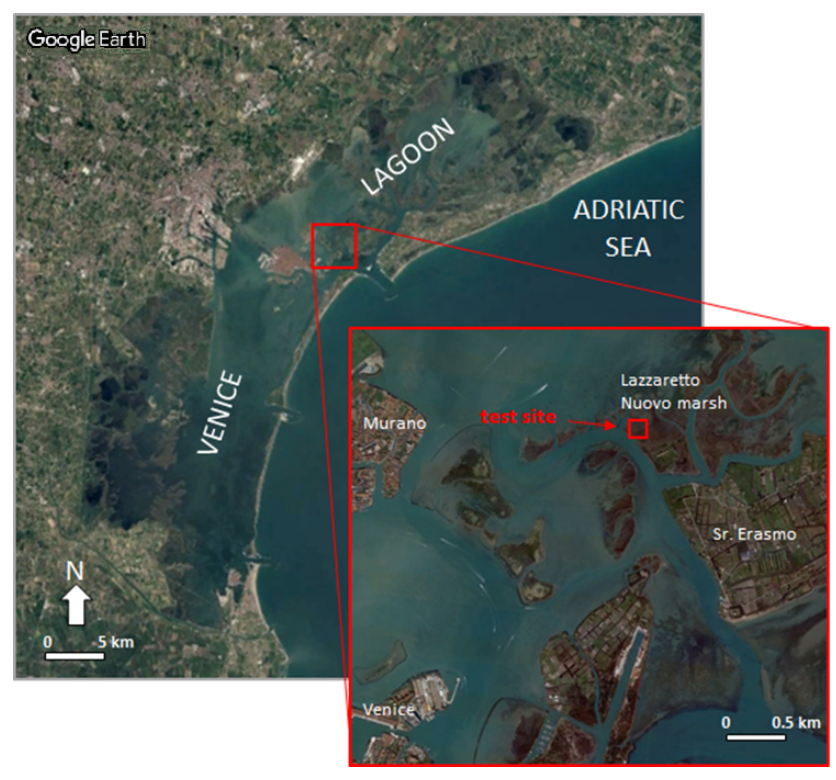

Figure 1. Location of the Lazzaretto Nuovo salt-marsh and the site where the loading test has been carried out.

This contribution mainly reports on the design of the loading experiment and its implementation with the aim that this approach may be implemented somewhere else. The collected records are finally illustrated.

\section{The study area}

The study area is a lagoon sector located about $5 \mathrm{~km} \mathrm{NW}$ of the Venice historical center and close to the Lido inlet, known as Lazzaretto Nuovo (Fig. 1). Specifically, the loading experiment was conducted in a portion of the saltmarsh bounded by lagoon channels and crossed by a branching network of tidal creeks, which allow the water exchange with the mudflats and ponds, thus enhancing the sediment transport and deposition above the marsh platform (Amos et al., 2010).

Nowadays, the amount of sediments entering the lagoon from the rivers is negligible. Thus, the main sources of sediments is erosion at the marsh fronts and on the lagoon bottom by waves, tides and other hydrodynamic processes, and sediment input through the lagoon inlets (Marani et al., 2011).

The elevation of the Lazzaretto Nuovo marsh, which is a natural marsh with the margins partially reinforced by stone-filled rolls to reduce erosion, ranges from 0.3 to $0.5 \mathrm{~m}$ a.s.l. (above sea level) on the strip banks of the channels and creeks. Depending on the surface elevation, different halophytic species of vegetation colonized the saltmarsh (Da Lio et al., 2013). The vegetation plays an important role in the sedimentation process since it favors the trapping of the suspended sediment transported on the top of the marshes during high tide events and contributes to organic soil production. This allows the saltmarshes to counteract relative 


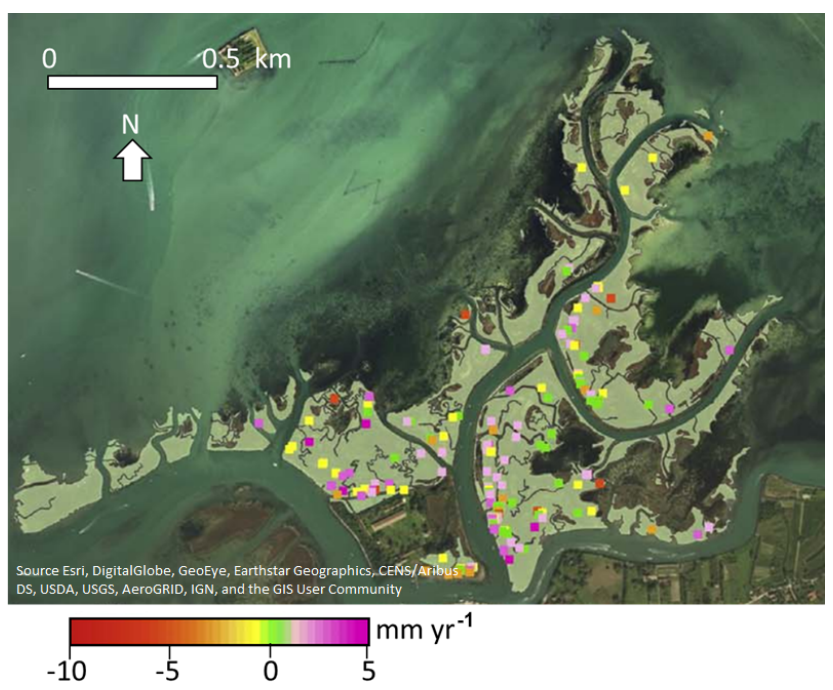

Figure 2. Lazzaretto Nuovo salt-marsh: average land displacement between 2008 and 2013 measured by PSI. Positive values mean uplift, negative values land subsidence. The red box shows the location of the loading experiment (modified after Da Lio et al., 2018).

sea-level rise, i.e. land subsidence combined with sea level rise due to climate changes (Rizzetto and Tosi, 2011).

An image of the surface movements of Lazzaretto Nuovo marsh is shown in Fig. 2. The measurements were obtained by Persistent Scattered Interferometry (PSI) on a stack of 143 TerraSAR-X stripmap images acquired between 2008 and 2013 with a regular $11 \mathrm{~d}$ revisiting time. Positive velocities were interpreted as accretion rates (Da Lio et al., 2018).

In the upper $1 \mathrm{~m}$, the saltmarsh deposit consists of silty clay and silt alternated with thin peaty layers, and abundant recent plant remains and root traces at the top. A picture of sediment cores and the grain size distribution of the silt in the $20-30 \mathrm{~cm}$ depth interval are shown in Fig. 3. Silt is the prevailing lithology of the salt-mashes located in the northern lagoon basin close to the actual littoral strips (Tonni et al., 2006; Biscontin et al., 2007; Cola et al., 2008). Mudflat deposits are composed mainly of clayey silt whereas channel units are medium to fine sand layers, often with shell fragments, interbedded by silt laminations. At the Lazzaretto marsh, the total thickness of the soft Holocene sediments amounts to 6 to $7 \mathrm{~m}$.

\section{Set-up of the loading experiment}

An in-situ loading experiment was carried out in July 2019 on the Lazzaretto Nuovo marsh to reliably characterize the hydro-geomechanical response of the shallow marsh deposits at low vertical effective stress levels when subjected to small vertical stress increments.

The execution of such a test has been very challenging from several points of view. The marsh is difficult to reach, the material transportation is not easy, the setting up of the

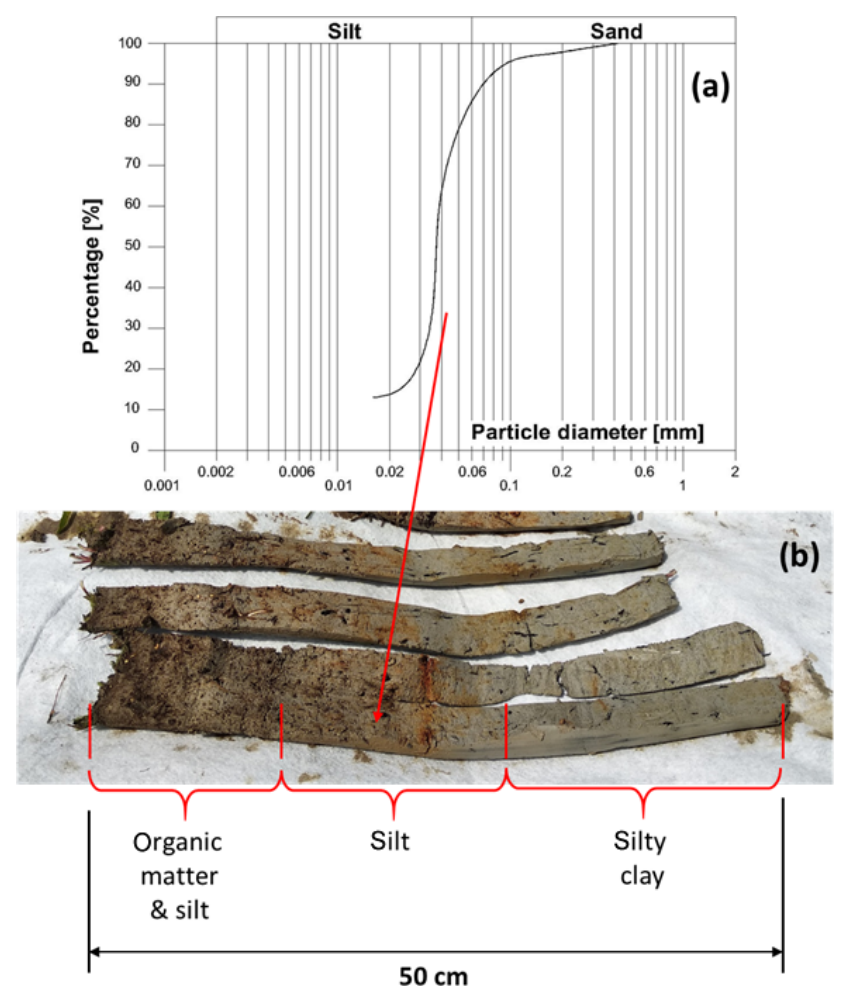

Figure 3. (a) Grain size distribution of a sample collected in the Lazzaretto Nuovo marsh at about $20 \mathrm{~cm}$ depth. (b) Picture of a $50 \mathrm{~cm}$ deep core drilled to establish one of the piezometers. The main lithological units are highlighted.

specific instrumentation required to track the evolution of the hydro-geomechanical parameters is not straightforward without disturbing the marsh soil, thus affecting the potential test results. In addition, the mash is flooded twice a day during high tides. Safety conditions for the researchers remaining on the marsh for a few consecutive days must also be guaranteed.

The load was represented by eight polyethylene tanks that, once put in the appropriate location, were filled with seawater. The tank dimensions are $78 \times 69 \times 104 \mathrm{~cm}^{3}$, can contain $500 \mathrm{~L}$, and their empty weigh is approximately $0.1 \mathrm{kN}$ each.

The tanks were arranged in two rows, each constituted by four tanks (Fig. 4a). This configuration allowed to transfer a sufficiently high load on a sufficiently large area, thus the assumption of vertical one-dimensional deformation is acceptable at least below the central portion of the system. A reinforced geotextile and four wooden pallets were put between the marsh surface and the tanks to guarantee a more uniform load distribution on the marsh platform and eliminate (or at least reduce) buoyancy forces on the tanks in high tide conditions (Fig. 4b). The tanks were separated by a $10 \mathrm{~cm}$ gap to allow for a correct working of the monitoring instrumentations. Consequently, the whole loading area is $2.5 \times 1.8 \mathrm{~m}^{2}$. The tanks were properly interconnected trough plastic tubes 


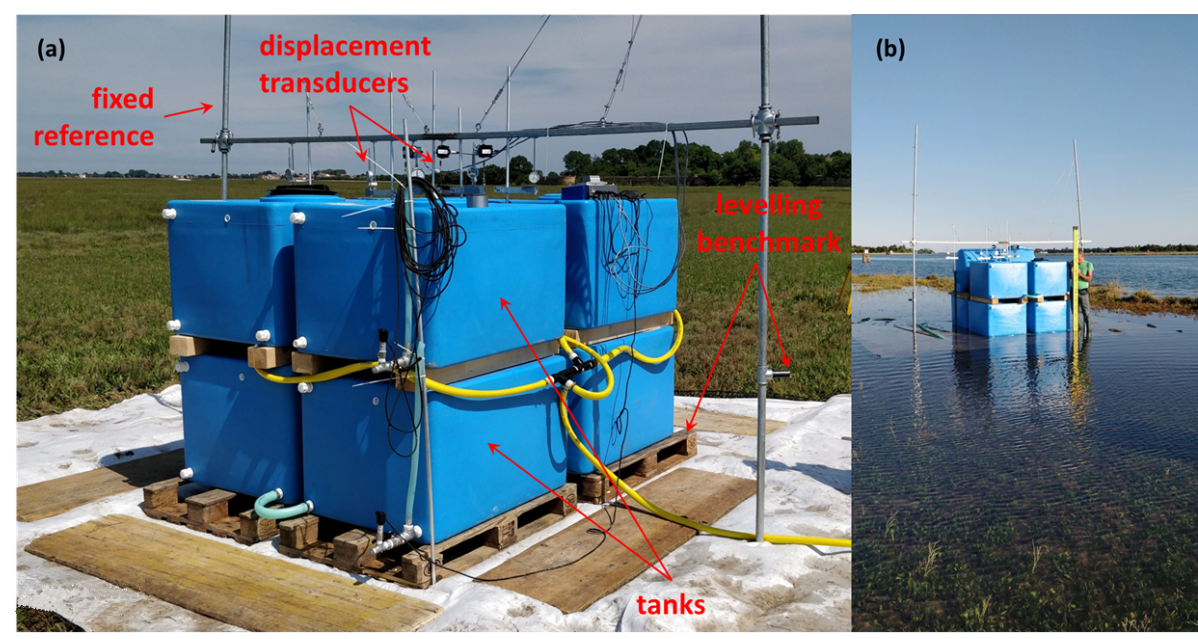

Figure 4. (a) Picture of the loading and monitoring equipment and (b) the experimental equipment in high-tide conditions with the marsh flooded by approximately $0.2 \mathrm{~m}$ sea water.
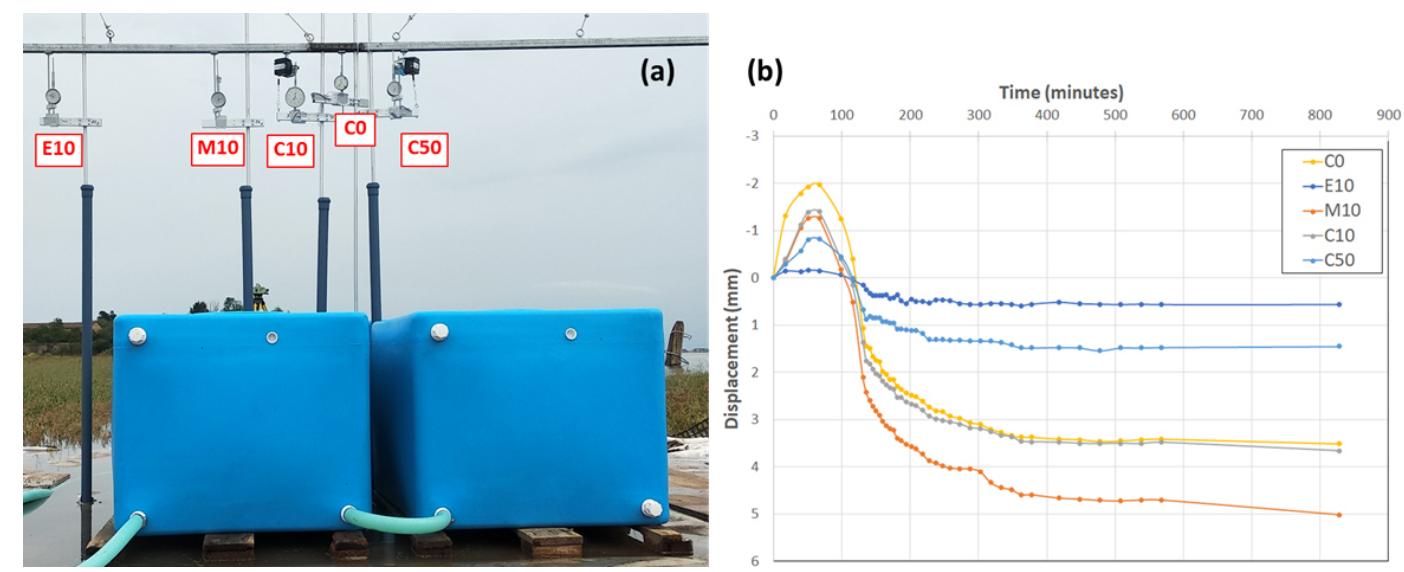

Figure 5. (a) Displacement transducers (C0: central position at the land surface; $\mathrm{C} 10$ : central position at $10 \mathrm{~cm}$ depth; M10: median position at $10 \mathrm{~cm}$ depth; E10: external position at $10 \mathrm{~cm}$ depth; C50: central position at $50 \mathrm{~cm}$ depth). (b) Displacements recorded during phase 2 unloading and phase 3 loading cycles; negative values mean uplift, positive subsidence.

to guarantee the same water levels during filling, which guarantees a uniformly distributed load.

We measured vertical displacements and groundwater pressure at various depths and locations below the load. A number of five dial indicators (Borletti SC $50,0.01 \mathrm{~mm}$ accuracy) were installed to measure the movements of the marsh surface, at 10 and $50 \mathrm{~cm}$ depth in the load center, just outside the load, and at an intermediate position (Fig. 5a). Each transducer is attached at one end to a H-shaped steel structure anchored on two piles set into the ground to a $6 \mathrm{~m}$ depth where an over-consolidated layer is located. The other end is fixed to the prescribed soil depth through an ad hoc aluminum anchor designed while taking into account the following two main constraints: (i) minimize the soil disturbance during the insertion at the reference depth; (ii) guarantee the anchor solidity with the soil at the depth of interest although the loose nature of the shallow deposits forming the tidal marsh. The anchor is constituted by a $5 \mathrm{~cm}$ radius helicoidal disk with a $0.5 \mathrm{~cm}$ diameter, $50 \mathrm{~cm}$ long wire in the center and is inserted into the soil by rotation only.

Before positioning the tanks, six water pressure loggers (ONSET Hobo U20-001-04-Ti, resolution $0.014 \mathrm{kPa}$, accuracy $\pm 0.3 \% \mathrm{FS}, 0.43 \mathrm{kPa}$ maximum error) were put into Casagrande filter units and established at depths ranging from 20 to $100 \mathrm{~cm}$ below the marsh surface. Similar to the displacement transducers, the pressure measurements were carried out directly below the load center, at the edge of the tanks and in intermediate positions (Fig. 6).

The displacements of the reference H-shaped steel structure and the four external corners of wooden pallets were checked during the whole test by means of very-high precision spirit levelling. A reference benchmark was established $50 \mathrm{~m}$ far from the load using a steel pole inserted into the soil at about $6 \mathrm{~m}$ depth. The tide was also measured in the 


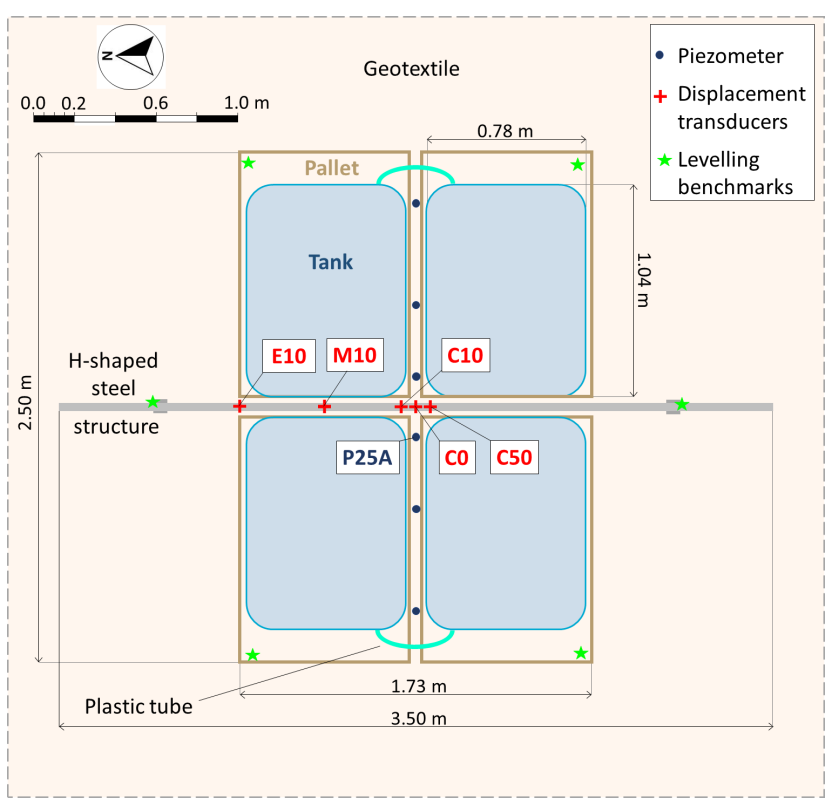

Figure 6. Sketch of the loading with dimensions and location of the monitoring instruments.

channel in front of the experimental apparatus. Also the tidal gauge equipment was connected to the same $6 \mathrm{~m}$ deep reference pole.

The movement of the material and researchers during the $4 \mathrm{~d}$ experiment period was also very challenging. This required the use of three boats. A large one was used to transport the bulky equipment, provide the power supply, and hosted the people at night and during a couple of severe thunderstorms that affected the northern Venice Lagoon on 8 and 9 July. A smaller one was used to as a "link" between the large boat, which cannot dock to the marsh margin for safety reason, and the marsh. The third one was devoted to the movements of the researchers that alternating remained on the marsh to collect the measurements and checked the ongoing experiment.

A set of wood boards was also placed on the marsh surface and used to reduce the loading disturbance induced by the people walking on the marsh during the apparatus establishment and the experimentation.

\section{The loading experiment and preliminary results}

The experiment was carried out from 8 to 11 July 2019, and consisted of various phases to characterize the geomechanical properties in virgin loading, unloading, and secondary compression conditions. The phases can be summarized as follows (Fig. 7):

1. a load of $\sim 2 \mathrm{kPa}$ (the bottom tanks were filled to the middle) was applied in half an hour, maintained over $3 \mathrm{~h}$, and then quickly removed;

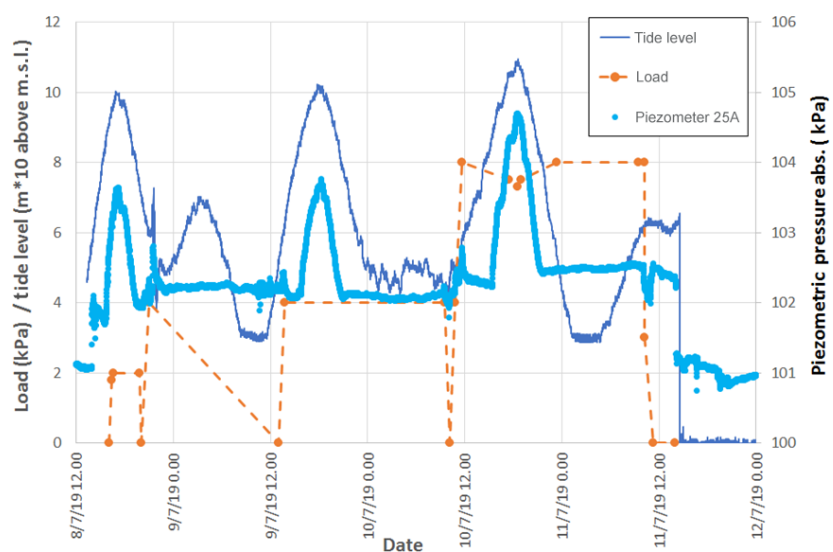

Figure 7. Time behavior of the applied load, tide level and pressure at piezometer $25 \mathrm{~A}$, which is $20 \mathrm{~cm}$ deep and at a distance of $15 \mathrm{~cm}$ from the load center (Fig. 6). The records cover the whole period of the loading test, i.e. from 8 July at 12:00 LT to 11 July at 14:00 LT.

2. a load of $\sim 4 \mathrm{kPa}$ (the four bottom tanks were completely filled) was applied in half an hour, maintained over $20 \mathrm{~h}$, and then quickly removed;

3. a load of $\sim 8 \mathrm{kPa}$ (all the eight tanks were completely filled) was applied in $1 \mathrm{~h}$, maintained over almost $24 \mathrm{~h}$, removed in $1 \mathrm{~h}$, and the monitoring prolonged over the next $3 \mathrm{~h}$.

The load path is schematically depicted with the dashed orange colored line in Fig. 7. Notice that phase 2 was repeated due to a severe thunderstorm with hail that partially destroyed the equipment. Consequently, we were able to monitor the system evolution only during the phase 2 repetition.

A few preliminary results of the test are provided in Figs. $5 b$ and 7 . Figure $5 b$ shows the displacements recorded by the various transducers over phase 2 unloading and phase 3 loading. As expected, the marsh body swelled when the load was removed and then compressed again when the eight tanks were filled. Generally, but not strictly, the shallower the reference depth and the closer the location to the center of the load, the larger is the recorded displacement.

Figure 7 compares the pressure recorded over the whole experiment by a $20 \mathrm{~cm}$ deep pressure transducer with the tidal fluctuation of the lagoon level and the load applied on the marsh surface. The groundwater pressure is significantly affected by the tide, but the effect exerted by the load application and removal is also clearly recorded.

\section{Conclusion}

An in-situ loading test has been carried out in July 2019 on the Lazzaretto Nuovo tidal marsh, a few km north-east of Venice. The test was carried out by means of original equipment specifically designed to meet the challenges of working in a tidal transitional environment. The test was composed of 
three loading and unloading cycles, with a maximum pressure exerted on the marsh surface that amounted to $\sim 8 \mathrm{kPa}$ over a $4.5 \mathrm{~m}^{2}$ area. A number of sensors recorded the vertical displacement of the marsh deposits and the groundwater pressure below the load at three depths and three distances from the central axis of the load. Due to the peculiarity of the environment and the softness of the marsh shallow deposits, the set-up and management of the experiment required a large effort.

Despite the adverse meteorological conditions that destroyed part of the instrumentation, the collected dataset seems valuable. Because of the complex geometry and the variability of the external conditions, namely a tidal fluctuation in the order of $1 \mathrm{~m}$, the measurement interpretation is not straightforward. This will be carried out by means of a threedimensional visco-elasto-plastic poromechanical model that, once properly calibrated, will allow characterizing the hydrological and geomechanical properties of the tidal marsh deposits. These properties will be finally used in long-term biomorpho-geomechanical simulations of tidal marsh evolution.

Data availability. Since the project is still ongoing, data are not available to the public. Data can be required to the funding agency. Data will become freely accessible at the end of the VENEZIA 2021 Research Programme expected in December 2021.

Author contributions. PT, LT, AB, PS, VG, PZ, CZ, MF and MM designed the experiment. PT, CD, LT, AB, SP, VG, PZ, CZ, $\mathrm{MR}, \mathrm{MM}, \mathrm{AD}$ and GZ carried out the experiment. PS, VG, PZ and SC carried out the lab testing. PT, CD, LT, AB, PS and VG wrote the paper.

Competing interests. The authors declare that they have no conflict of interest.

Special issue statement. This article is part of the special issue "TISOLS: the Tenth International Symposium On Land Subsidence - living with subsidence". It is a result of the Tenth International Symposium on Land Subsidence, Delft, the Netherlands, 17-21 May 2021.

Acknowledgements. This article is an outcome of the VENEZIA-2021 Research Programme, Topic 3.1, funded by the "Provveditorato Interregionale Opere Pubbliche per il Veneto, Trentino Alto Adige e Friuli Venezia Giulia" through the "Concessionario Consorzio Venezia Nuova" and coordinated by CORILA, Venice. The authors gratefully acknowledge the great assistance in the field provided by the crew of the research boat Litus (CNR-ISMAR) Daniele Penzo, Mauro Penzo, and Gianni Zennaro.
Financial support. This research has been supported by the Provveditorato Interregionale Opere Pubbliche per il Veneto, Trentino Alto Adige e Friuli Venezia Giulia (grant no. VENEZIA2021 Research Programme, Topic 3.1).

\section{References}

Allen, J. R. L.: Geological impact on coastal wetland landscapes: some general effects of sediment auto-compaction in the Holocene of northwest Europe, Holocene, 9, 1-12, https://doi.org/10.1191/095968399674929672, 1999.

Amos, C. L., Umgiesser, G., Tosi, L., and Townend, I. H.: The coastal morphodynamics of Venice lagoon, Italy: An introduction, Cont. Shelf Res., 30, 837-846, https://doi.org/10.1016/j.csr.2010.01.014, 2010.

Biscontin, G., Cola, S., Pestana, J. M., and Simonini, P.: Unified compression model for Venice lagoon natural silts, J. Geotech. Geoenviron. Eng., 133, 932-942, 2007.

Brain, M. J., Kemp, A. C., Horton, B. P., Culver, S. J., Parnell, A. C., and Cahill, N.: Quantifying the contribution of sediment compaction to late Holocene salt-marsh sea-level reconstruction, North-Carolina, USA, Quaternary Res., 83, 1151, https://doi.org/10.1016/j.yqres.2014.08.003, 2015.

Brain, M. J., Kemp, A. C., Hawkes, A. D., Engelhart, S. E., Vane, C. H., Cahill, N., Hill, T. D., Donnelly, J. P., and Horton, B. P.: Exploring mechanisms of compaction in salt-marsh sediments using Common Era relative sealevel reconstructions, Quaternary Sci. Rev., 167, 96-111, https://doi.org/10.1016/j.sedgeo.2010.10.005, 2017.

Cahoon, D. R., Lynch, J. C., Hensel, P., Boumans, R., Perez, B. C., Segura, B., and Day Jr., J. W.: High-precision measurements of wetland sediment elevation: 1 . Recent improvements to the sedimentation-erosion table, J. Sediment Res., 72, 730-733, https://doi.org/10.1306/020702720730, 2002.

Cola, S. and Simonini, P.: Mechanical behavior of silty soils of the Venice lagoon as a function of their grading characteristics, Can. Geotech. J., 39, 879-893, 2002.

Cola, S., Sanavia, L., Simonini, P., and Schrefler, B. A.: Coupled thermohydromechanical analysis of Venice lagoon salt marshes, Water Resour. Res., 44, W00C05, https://doi.org/10.1029/2007WR006570, 2008.

Da Lio, C., D'Alpaos, A., and Marani, M.: The secret gardener: vegetation and the emergence of biogeomorphic patterns in tidal environments, Philos. T. Roy. Soc. A, 371, 20120367 , https://doi.org/10.1098/rsta.2012.0367, 2013.

Da Lio, C., Teatini, P., Strozzi, T., and Tosi, L.: Understanding land subsidence in salt marshes of the Venice Lagoon from SAR Interferometry and ground-based investigations, Remote Sens. Environ., 205, 56-70, https://doi.org/10.1016/j.rse.2017.11.016, 2018.

D'Alpaos, A. and Marani, M.: Reading the signatures of biologic-geomorphic feedbacks in saltmarsh landscapes, Adv. Water Resour., 93, 265-275, https://doi.org/10.1016/j.advwatres.2015.09.004, 2016.

Jankowski, K. L., Törnqvist, T. E., and Fernandes, A. M.: Vulnerability of Louisiana's coastal wetlands to present-day rates of relative sea-level rise, Nat. Commun., 8, 14792, https://doi.org/10.1038/ncomms14792, 2017. 
Lesser, G. R., Roelvink, J. A., van Kester, J. A. T. M., and Stelling, G. S.: Development and validation of a threedimensional morphological model, Coast. Eng., 51, 883-915, https://doi.org/10.1016/j.coastaleng.2004.07.014, 2004.

Marani, M., D'Alpaos, A., Lanzoni, S., Carniello, L., and Rinaldo, A.: The importance of being coupled: Stable states and catastrophic shifts in tidal bio-morphodynamics, J. Geophys. Res., 115, F04004, https://doi.org/10.1029/2009JF001600, 2010.

Marani, M., D’Alpaos, A., Lanzoni, S., and Santalucia, M.: Understanding and predicting wave erosion of marsh edge, Geophys. Res. Lett., 38, L21401, https://doi.org/10.1029/2011GL048995, 2011.

Morton, R. A., Ward, G. H., and White, W. A.: Rates of sediment supply and sea-level rise in a large coastal lagoon, Mar. Geol., 167, 261-284, https://doi.org/10.1016/S0025-3227(00)00030-X, 2000.

Rizzetto, F. and Tosi, L.: Aptitude of modern salt marshes to counteract relative sea-level rise, Venice Lagoon (Italy), Geology, 39, 755-758, https://doi.org/10.1130/G31736.1, 2011.

Serandrei-Barbero, R., Albani, A., Donnici, S., and Rizzetto, F.: Past and recent sedimentation rates in the Lagoon of Venice (Northern Italy), Estuar. Coast. Shelf Sci., 69, 255-269, https://doi.org/10.1016/j.ecss.2006.04.018, 2006.
Tonni, L., Cola, S., and Pastor, M.: A generalized plasticity approach for describing the behaviour of silty soils forming the Venetian lagoon basin, in: Proc. of the 6th Eur. Conf. on Numerical Methods in Geotechnical Engineering, 6-8 September 2006, Graz, Austria, 93-99, 2006.

Törnqvist, T. E., Wallace, D. J., Storms, J. E. A., Wallinga, J., Dam, R. L., Blaauw, M., Derksen, M. S., Klerks, C. J. W., Meijneken, C., A., and Snijders, E. M. A.: Mississippi Delta subsidence primarily caused by compaction of Holocene strata, Nat. Geosci., 1, 173-176, https://doi.org/10.1038/ngeo129, 2008.

van Asselen, S., Karssenberg, D., and Stouthamer, E.: Contribution of peat compaction to relative sea-level rise within Holocene deltas, Geophys. Res. Lett., 38, L24401, https://doi.org/10.1029/2011GL049835, 2011.

Zoccarato, C. and Teatini, P.: Numerical simulations of Holocene salt-marsh dynamics under the hypothesis of large soil deformations, Adv. Water Resour., 110, 107-119, https://doi.org/10.1016/j.advwatres, 2017.

Zoccarato, C., Minderhoud, P. S. J., and Teatini, P.: The role of sedimentation and natural compaction in a prograding delta: Insights from the mega Mekong delta, Vietnam, Scient. Rep., 8, 11437, https://doi.org/10.1038/s41598-018-29734-7, 2018. 